Paper

\title{
Effects of 5 IU oxytocin bolus and 20 IU oxytocin infusion compared to 5 IU oxytocin bolus and normal saline infusion in the control of blood loss during and after ante-partum lower segment caesarean section: a randomized controlled trial
}

\author{
J Kajendran, G R C Silva, S K Ranaraja
}

\begin{abstract}
Introduction Obstetric haemorrhage is the leading cause of maternal mortality worldwide and in most cases it relates to uterine atony. Even though an oxytocin bolus is used routinely, additional infusion of oxytocin may be required if haemorrhage occurs.
\end{abstract}

Objectives To compare the effects of 20 IU oxytocin infusion and $5 \mathrm{IU}$ bolus with $5 \mathrm{IU}$ bolus and $500 \mathrm{ml}$ normal saline on the control of blood loss in antepartum lower segment caesarean section.

Methods A double-blind randomized controlled trial was conducted in the Teaching Hospital, Peradeniya, Sri Lanka. Ninety two pregnant women, forty six from each group were randomized to receive either intravenous slow 5 IU oxytocin bolus over 1 minute and additional $20 \mathrm{IU}$ oxytocin infusion in $500 \mathrm{ml}$ of $0.9 \%$ saline solution over 4 hours (Group-A) or $5 \mathrm{IU}$ oxytocin bolus over 1 minute and $500 \mathrm{ml}$ of $0.9 \%$ Saline over 4 hours (Group B). Visual assessment of mean blood loss was done by the surgeon and anaesthetist. Blood loss was calculated based on the body weight and haematocrit before and 48 hours after delivery.

Results Calculated mean blood loss $(456.0 \mathrm{ml}$ vs $569.8 \mathrm{ml})$ was significantly less in group A $(p=0.046)$. Visual estimation of blood loss by surgeon (476.9 vs $552.1)(p=0.01)$ and anaesthetist (492.7 vs 557.2) ( $p=$ 0.03 ) were also significantly less in group A.

Conclusion Additional oxytocin infusion at antepartum caesarean section reduces blood loss during and after caesarean section significantly.

Ceylon Med J 2017;62: 121-127

DOI: http://doi.org/10.4038/cmj.v62i3.8515

\section{Introduction}

Caesarean section is one of the most commonly performed major operations in women throughout the world [1]. The caesarean section rate in Sri Lanka in 2013 was 31.3\% [2]. Operative morbidity due to caesarean section includes haemorrhage, anaemia, blood transfusion and the risks associated with receiving donor blood products $[3,4]$. In extreme cases it may result in hysterectomy, admission to an intensive care unit or even maternal death [5]. According to a WHO report which was published in 2014 major obstetric haemorrhage is the leading cause of maternal mortality worldwide and in most cases it relates to uterine atony [6]. According to the Annual Health Bulletin 2013, postpartum haemorrhage is the leading cause of maternal mortality in Sri Lanka [7].

Intravenous oxytocin has a very short half-life (4-10 minutes) hence an oxytocin infusion can maintain uterine contractility throughout surgery and in the immediate postpartum period [8]. That is the most susceptible period when most primary haemorrhages occur. Reduction of blood loss will be instrumental in bringing down the post-operative morbidity $[9,10]$. It will also assist in averting potential problems in blood transfusion [11]. The third stage at the caesarean section has not been duly managed [12]. The current practices of oxytocin administration are not uniform [13]. The value of routine oxytocin in the third stage of vaginal birth has been well established and it has been assumed that these benefits apply to caesarean section as well $[14,15]$.

Obstetrics and Gynaecology Unit, Teaching Hospital Peradeniya, Peradeniya, Sri Lanka. Correspondence: JK, E-mail: <kajendranj@yahoo.com>.Received 20 April 2017 and revised 
In line with latest guidelines by the Royal College of Obstetricians and Gynaecologists on actively managing labour in its third stage, a slow intravenous bolus dose of $5 \mathrm{IU}$ of oxytocin is recommended to be administered after delivery [16]. This dose is based on the principles of active management of the third stage of labour. During routine use of an intravenous oxytocin bolus, additional oxytocin is administered in case of a haemorrhage. This practice is on the rise either selectively or as a routine even when there is no need [17]. It is also observed that the administration of a oxytocin bolus is carried out sometimes with and sometimes without the additional dosage [18]. In Sri Lanka there is a wide variation in the use of an oxytocin infusion in addition to the bolus following caesarean section. Most clinicians intervene in the event of uterine atony by administering an additional uterotonic agent. However, there is very limited evidence to guide practice.

Studies have compared use of an oxytocin infusion in addition to the bolus during caesarean section. However, the evidence is inadequate to recommend oxytocin infusion over IV bolus injection [19]. One study compared the effects of a 5 IU oxytocin bolus and placebo infusion versus a 5 IU oxytocin bolus and $30 \mathrm{IU}$ infusion on the control of blood loss at elective caesarian section and it reported that mean estimated blood loss was lower in the oxytocin infusion arm (5 IU oxytocin bolus and 30 IU infusion) compared to placebo (5 IU oxytocin bolus and placebo infusion) and fewer women had a major haemorrhage or required an additional uterotonic agent [20]. However, another study which compared 5 IU oxytocin bolus and $40 \mathrm{IU}$ infusion to placebo revealed that there was no significant difference in mean blood loss [21]. Therefore, this study aims to compare a standard 5 IU bolus of oxytocin and an additional 20 IU oxytocin infusion (bolus and infusion) with a 5 IU bolus of oxytocin and placebo infusion (bolus only), to determine whether the use of an inexpensive and widely used drug can further improve prevention of hemorrhage at caesarian section.

\section{Method}

A double-blind, placebo controlled randomized trial was conducted in an obstetric unit at Teaching Hospital, Peradeniya, Sri Lanka, which is a leading tertiary care hospital in the country. Pregnant women, who were at term, with singleton pregnancies and had a planned elective caesarian section were selected for the study. Sample size was calculated based on the measured blood loss in women following caesarian section, taking mean blood loss with the use of oxytocin as $900 \mathrm{ml}(\mathrm{SD}=500 \mathrm{ml})$. Assuming that adding $20 \mathrm{IU}$ infusion in addition to bolus will further reduce blood loss by $300 \mathrm{ml}$, a sample of 46 subjects in each group was required to detect the difference at $90 \%$ power at 5\% significance (Figure 1).

Exclusion criteria were women who were in established labour, had multiple pregnancies, established or suspected cases of chorioamnionitis, both minor and major degree placenta praevia and established or suspected cases of placental abruption, previous history of postpartum haemorrhage and coagulation disorders, and women with a history of or had ultrasonically proven fibroids.

Randomization was done using computergenerated random numbers. Sequentially numbered and sealed, opaque envelopes coded with the appropriate dose regimen were prepared by the supervisor. Anaesthetist who gave anaesthesia during the caesarian section and the investigator were blinded. Principles of allocation concealment and double blinding were followed. An anaesthetist, who was not involved in the management of women during and after the caesarian section received an envelope when the woman was sent to operating theatre. According to the information in the sealed envelope, either the placebo or active infusion was prepared and given to the anaesthetist who gave the anesthesia and was involved in management. While inserting the cannula before anesthesia $3 \mathrm{ml}$ of blood was taken from each woman in a Vacutainer plastic tube (Hunan Liyang Medical instrument factory, China) with ethylene diamine tetra acetic acid and sent for assessment of full blood count. Full blood count was checked by using Mindray BC3000 plus Haematology Analyser (Mindray, Shenzen,China). Haemoglobin concentration, packed cell volume, platelets and other blood cells concentration were assessed. All patients who underwent spinal anaesthesia received an intravenous bolus of $500 \mathrm{ml}$ normal saline before spinal anaesthesia. Surgical and anaesthetic techniques were standardized to both groups of study. Before caesarian section, a $16 \mathrm{Fr}$ Foley catheter was inserted and the abdomen was cleaned with povidone iodine solution. Pfannenstiel incisions were performed in all patients. Routine caesarian section was performed with transverse lower uterine segment incision followed by delivery of the foetus and placenta. The placenta was delivered by controlled cord traction. A 5 IU intravenous bolus of oxytocin over 5-10 seconds was injected to each woman by the anaesthetist when the umbilical cord clamping was being done. Then in group A patients, 20 IU oxytocin in $500 \mathrm{ml}$ of $0.9 \%$ normal saline solution was continued at a rate of 125 
$\mathrm{ml} /$ hour for four hours and in group B patients $500 \mathrm{ml}$ of $0.9 \%$ normal Saline solution at a rate of $125 \mathrm{~m} /$ hour was continued for four hours. If the uterus remains atonic despite the trial intervention, the obstetrician or anaesthetist could use an additional uterotonic agent by replacing the trial infusion with a known oxytocin infusion or by using other additional agents. The uterine atony was detected by the surgeon during surgery and by skilled birth attendants in the postnatal ward. Pulse rate, respiratory rate, blood pressure and oxygen saturation percentage were monitored every 15 minutes during the procedure.

Identical standard of postpartum care was provided for both groups who were managed in the same postnatal ward by the same staff. Vital signs (pulse rate, respiratory rate, blood pressure and oxygen saturation percentage) were checked every 15 minutes in the first 2 hours, every 30 minutes in second 2 hours and hourly for another 2 hours and continued 4 hourly for 24 hours. Urine output was monitored hourly for 6 hours. The need for additional uterotonic agents for the management of intraoperative and postoperative uterine atony was recorded. Full blood count was repeated at 48 hours postoperative. Preoperative PCV, haemoglobin and post-operative PCV and haemoglobin values were recorded. The blood loss was calculated through the difference in the haematocrit values assessed prior to and 48 hours after caesarean section according to the following formula $[22,23]$. Calculated blood loss - estimated blood volume $\mathrm{x}$ (preoperative packed cell volume - postoperative packed cell volume) /preoperative packed cell volume. Estimated blood volume in $\mathrm{ml}$ was estimated by multiplying the woman's weight in kilograms x 85 .

Blood loss estimation was done using above formula as a quantitative objective measure to estimate blood loss because it is widely accepted that clinicians underestimate blood loss visually and that gravimetric methods include liquor in addition to blood, which limits accuracy $[24,25,26]$. Disposable waterproof drapes with pockets that capture blood and liquor were not used due to financial constraints. Visual estimation and accepted calculation method were chosen to estimate blood loss [20,21]. Need for additional uterotonic and occurrence of adverse effects such as nausea, vomiting and arrhythmias was recorded.

Ethical approval was obtained from the Ethical Review Committee, Faculty of Medicine, University of Peradeniya, Sri Lanka. Trial was registered in the Sri Lanka Clinical Trial Registry (SLCTR/2013/019, 29 ${ }^{\text {th }}$ May 2013). Prior approval was obtained from the Director, Teaching Hospital, Peradeniya, Sri Lanka. Strict confidentiality of the data was ensured. Women were recruited to the trial in the third trimester when they got admitted for a planned elective caesarian section. An investigator or an assistant approached eligible women and explained about the study. Consenting women were recruited after explaining about the intervention and associated risks. Written informed consent was obtained from all participants.

Descriptive statistics were used to summarize the data. Measures of dispersion and 95\% confidence intervals were calculated. For comparisons of continuous variables Student's T test was used when the data were normally distributed. For variables with a skewed distribution median, inter-quartile range, Mann- Whitney U test were used. Chi-square test was used to look for associations between categorical variables. Relative risk (RR) with 95\% confidence interval (CI) was calculated. A p-value of less than 0.05 was considered as statistically significant.

\section{Results}

Ninety two mothers were recruited for the study (46 in each group). Demographic details of the sample are presented in Table 1. There were no significant differences in age, BMI, parity or period of amenorrhoea between the treatment groups. Table 2 shows that the oxytocin bolus and infusion group (intervention group) had significantly lower mean calculated blood loss, lower visual estimation of blood losses by surgeon ( 476.9 vs. 552.1$)(p=0.01)$ and by the anaesthetist (492.7 vs. 557.2) $(p=0.03)$. However, there was no significant difference in occurrence of major obstetric haemorrhage $(p=0.153)$, change in heamoglobin concentration or packed cell volume. There was no significant difference in need for additional uterotonic agent or interventions following blood loss (Table 3). None of the participants needed surgical intervention, uterine artery ligation, B-lynch / compression sutures, total or subtotal hysterectomy or internal iliac artery ligation. There was no significant differences in mean duration of surgery between the intervention group 30.4 minutes $(\mathrm{SD}=11.6)$ and the control group 30.0 minutes $(\mathrm{SD}=11.6),(p=0.4)$. There was no significant difference in mean length of stay in theatre and recovery in the intervention group 116.6 minutes $(\mathrm{SD}=56.0)$ and the control group 112.6 minutes $(\mathrm{SD}=46.8)(p=0.08)$. Side effects of oxytocin such as nausea and vomiting were reported in two subjects in the intervention group and in one subject in the control group. 


\section{Discussion}

In this trial, women delivered by caesarian section had significantly less blood loss during and after caesarian section when 20 IU oxytocin infusion was given in addition to $5 \mathrm{IU}$ oxytocin bolus compared to those who received 5 IU oxytocin and a normal saline infusion.

A study carried out to assess effects of $40 \mathrm{IU}$ of oxytocin infusion in addition to slow intravenous 5IU bolus found no difference in the occurrence of major obstetric haemorrhage (blood loss more than $1000 \mathrm{ml}$ ) between the groups [21]. The need for an additional uterotonic agent in the bolus and infusion group was lower than in the bolus only group. There were no significant difference in any of the secondary outcomes such as mean calculated blood loss, mean fall in haemoglobin and mean measured blood loss. Even though that study standardized the surgical technique, different surgeons both junior and senior obstetricians, carried out the caesarian sections [21]. But in our study the caesarian sections were done by one surgeon.

Another double-blind, placebo-controlled study was done on 720 women to assess the effects of a $5 \mathrm{IU}$ oxytocin bolus and placebo infusion versus $5 \mathrm{IU}$ oxytocin bolus and $30 \mathrm{IU}$ infusion, on the control of blood loss at elective lower segment caesarean section. Blood loss was estimated based on the haematocrit values before and 48 hours after delivery. Mean estimated blood loss and the proportion of women with blood loss estimated to be greater than $1000 \mathrm{ml}$ were significantly less in the oxytocin infusion group. They used lactated Ringer's solution as placebo and caesarian sections were performed by different surgeons. Even though it was done with a larger sample size, it has also yielded similar outcomes as our study [20]. Another study compared the blood loss at elective lower segment caesarian section with administration of oxytocin 5 IU bolus versus oxytocin 5 IU bolus and oxytocin 30 IU infusion [24]. A randomized trial among 115 women has showed that additional oxytocin infusion at elective caesarian section may reduce blood loss and maternal morbidity [27].

The amount of blood loss in our study (120 $\mathrm{ml})$ was not clinically significant. The intervention did not affect occurrence of major obstetric haemorrhage or the need for additional uterotonic agents or blood transfusion. Use of an oxytocin infusion after an initial bolus did not increase the occurrence of side effects. The sample was not calculated to detect differences in occurrence of major obstetric haemorrhage, need for additional uterotonics or blood transfusion. Therefore, valid conclusions cannot be drawn about these outcomes. Women with risk factors associated with postpartum haemorrhage were excluded because of the different preventive measures undertaken in these women. In this study blood loss at the time of caesarean section was visually estimated and total blood loss was calculated by using preoperative and postoperative packed cell volume. But if the blood loss was measured by using the weighing method it may have been more accurate. The strength of our study is that all caesarian sections were performed by a single surgeon and techniques of surgery and anaesthesia were standardized.

In conclusion, additional oxytocin infusion at ante-partum caesarean section reduces blood loss during and after caesarean section significantly. The implementation of these findings in clinical practice merits special attention. One option is to administer oxytocin bolus and infusion to all women who undergo antepartum caesarian section. This may help circumvent the problem of having to determine the time of administering uterotonic agent. The negative side of this approach is that some women who do not need an infusion may receive it. Another option is to administer the additional oxytocin infusions during antepartum caesarian section to selected women.

\section{Acknowledgement}

We express our sincere gratitude to the pregnant women who participated in this study.

\section{Conflicts of interest}

There are no conflicts of interest.

\section{References}

1. Lewis $G$ (ed). The Confidential Enquiry into Maternal and Child Health (CEMACH). Saving Mothers Lives; Reviewing Maternal Deaths to Make Motherhood Safer 2003-05. The Seventh Report of the United Kingdom Confidential Enquiries into Maternal Deaths in the United Kingdom. London: CEMACH, 2007Available at http; //www.cmace.org.uk. (accessed 9 March 2016).

2. Family Health Bureau. Annual Health statistics 2013.Ministry of Health, Colombo, Sri Lanka. Available at http://www.familyhealth.gov.lk. (accessed on 14 March 2015). 
3. Creanga AA, Bateman BT, Butwick AJ, et al. Morbidity associated with cesarean delivery in the United States: is placenta accreta an increasingly important contributor? Am J Obstet Gynecol 2015; 384: $1-11$.

4. Waterstone M, Bewley S, Charles Wolfe C. incidence and predictors of severe obstetric morbidity: case-control study. BMJ 2001; 322: 1089-94.

5. Clark SL, Belfort MA, Dildy GA, et al. Maternal death in the 21st century: causes, prevention, and relationship to cesarean delivery. Am J Obstet Gynecol 2008; 199: 1-5.

6. Say L, Chou D, Gemmill A, et al. Global Causes of Maternal Death: A WHO Systematic Analysis. Lancet Glob Health 2014; 2: 323-33.

7. Attygalle D. Global survey on maternal and perinatal health in Asia 2007-2008: Sri Lanka Country Report. Family Health Bureau, Ministry of Healthcare and Nutrition, Sri Lanka 2009.

8. Sarna MC, Soni AK, Gomez M, et al. Intravenous oxytocin in patients undergoing elective caesarean section. Anesth Analg 1997; 84: 753-6.

9. Dansereau J, Joshi AK, Helewa ME, et al. Doubleblind comparison of carbetocin versus oxytocin in prevention of uterine atony after cesarean section. Am J Obstet Gynecol 1999; 180: 670-6.

10. Thomas JS, Koh S, Cooper G. Haemodynamic effects of oxytocin given as i.v. bolus or infusion on women undergoing ceasarean section. $\mathrm{Br} \mathrm{J}$ Anaesth 2007; 98: 116-9.

11. Dahlke JD, Mendez-Figueroa H, Rouse DJ, et al. Evidence-based surgery for cesarean delivery: An updated systematic review. Am J Obstet Gynecol 2013; 209: 294-306.

12. Wedisinghe L, Macleod M, Murphy DJ. Use of oxytocin to prevent haemorrhage at caesarean section-a survey of practice in the United Kingdom. Eur J Obstet Gynecol Reprod Biol 2008; 137: 27-30.

13. Dyer RA, van Dyk D, Dresner A. The use of uterotonic drugs during Caesarean section. Inter $J$ Obstet Anaesth 2010; 19: 313-9.

14. Westhoff G, Cotter AM, Tolosa JE. Prophylactic oxytocin for the third stage of labour to prevent postpartum haemorrhage.Cochrane Database Syst Rev. 2013; 30. CD001808.

15. Lokugamage AU, Paine M, BassawBalroop K, et al. Active management of the third stage at caesarean section: a randomised controlled trial of misoprostol versus syntocinon. Aust $N Z J$ Obstet Gynaecol 2001; 41: 411-4.
16. Royal College of Obstetricians and Gynaecologists. Prevention and treatment of postpartum haemorrhage.Green-top Guideline No.52, RCOG 2009. Available at: http://www.rcog.org.uk. (accessed on 20th May 2016).

17. Tsen LC, Balki M. Oxytocin protocols during cesarean delivery: time to acknowledge the risk/benefit ratio? Int J Obstet Anesth 2010; 19: 243-5.

18. Mockler JC, Murphy DJ, Wallace EM. An Australian and New Zealand survey of practice of the use of oxytocin at elective caesarean section. Aust N Z J Obstet Gynaecol 2010; 50: 30-5.

19. World Health Organization. Recommendations for the Prevention and treatment of Postpartum Hemorrhage. Geneva: WHO, Geneva 2012.

20. Güngördük K1, Asicioglu $\mathrm{O}$, Celikkol $\mathrm{O}$, et al. Use of additional oxytocin to reduce blood loss at elective caesarean section? A randomized control trial. Aust N Z J Obstet Gynaecol 2010; 50: 36-9.

21. Sheehan SR, Montgomery AA, Carey M, et al. Oxytocin bolus versus oxytocin bolus and infusion for control of blood loss at elective caesarean section: Double blind, placebo controlled, randomized trial. BMJ 2011; 343: 4661.

22. Carvalho JC, Balki M, Kingdom J, et al. Oxytocin requirements at elective cesarean delivery: a dosefinding study. Obstet Gynecol 2004; 104: 1005-10.

23. Shook PR, Schultz JR, Reynolds JD, et al. Estimating blood loss for cesarean section: how accurate are we? Anesthesiology 2003; 98: 1-19.

24. Stafford I, Dildy GA, Clark SL, et al. visually estimated and calculated blood loss in vaginal and cesarean delivery. Am J Obstet Gynecol 2008; 199: 519.e1-519.e7.

25. Duthie SJ, Ven D, Yung GLK, et al. Discrepancy between laboratory determination and visual estimation of blood loss during normal delivery. Eur J Obstet Gynecol Reprod Biol 1991; 38: 11924.

26. Walsh CA, Manias T, Brockelsby J. Relationship between haemoglobin change and estimated blood loss after delivery. Br J Obstet Gynaecol 2007; 114: 1447-8.

27. Murphy DJ, MacGregor H, Munishankar B, McLeod G. A randomised controlled trial of oxytocin 5IU and placebo infusion versus oxytocin 5IU and 30IU infusion for the control of blood loss at elective caesarean section--pilot study. Eur $J$ Obstet Gynecol Reprod Biol 2009; 142: 30-3. 
Table 1. Demographic and clinical characteristics of the intervention and control groups

\begin{tabular}{|c|c|c|c|}
\hline Demographic characteristics & $\begin{array}{l}\text { Oxytocin bolus and } \\
\text { infusion } \\
\text { Mean (SD) }\end{array}$ & $\begin{array}{l}\text { Oxytocin bolus and } \\
\text { placebo infusion } \\
\text { Mean (SD) }\end{array}$ & $P$ value \\
\hline Age & $30.7(4.5)$ & $29.9(4.7)$ & 0.41 \\
\hline BMI & $26.8(3.4)$ & $27.1(3.3)$ & 0.66 \\
\hline \multirow[t]{2}{*}{ Period of amenorrhoea } & $38.6(0.95)$ & $38.7(0.96)$ & 0.83 \\
\hline & \multicolumn{2}{|l|}{ Median (inter quartile range) } & \\
\hline Parity & $2(1)$ & $1(1)$ & 0.78 \\
\hline
\end{tabular}

Table 2. Comparisons of blood loss between intervention and control groups

\begin{tabular}{llll}
\hline & $\begin{array}{l}\text { Oxytocin bolus } \\
\text { infusion } \\
\text { Mean (95\% CI) }\end{array}$ & and $\begin{array}{l}\text { Oxytocin } \\
\text { placebo }\end{array}$ & bean (95\% CI) \\
\hline Drop in Hb (mg/dL) & $1.37(1.1-1.6)$ & $1.40(1.1-1.7)$ & 0.92 \\
Drop in PCV & $3.28(2.7-3.9)$ & $4.08(3.4-4.7)$ & 0.07 \\
Calculated blood loss $\mathbf{m l}$ & $455(381-531)$ & $569(485-654)$ & 0.046 \\
\hline
\end{tabular}

Table 3. Comparison of interventions following blood loss in the intervention and control groups

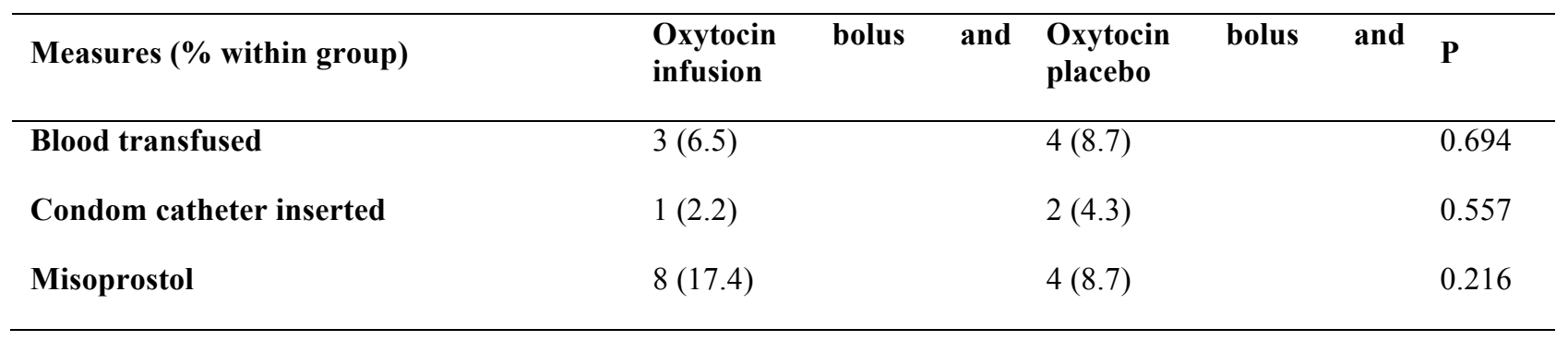




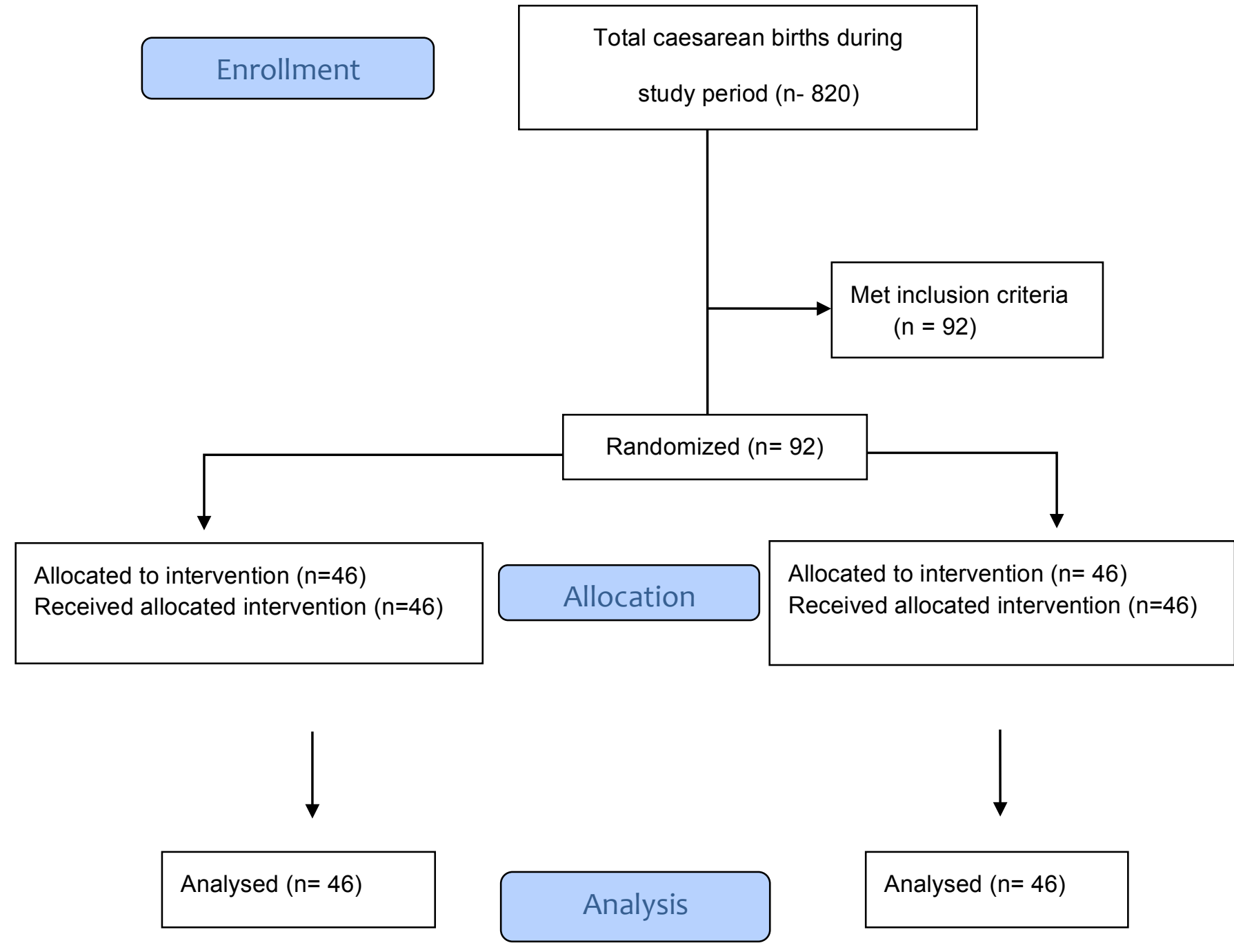

Figure 1. CONSORT flow chart

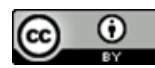

This is an open-access article distributed under the terms of the Creative Commons Attribution License, which permits unrestricted use, distribution, and reproduction in any medium, provided the original author and source are credited. Version accepted 24 July 2017. 